\title{
Long Range Backhaul Microwave Connectivity in Wireless Sensor Networks via a New Antenna Designed for ISM 2.4 GHz Band
}

\author{
Syed Mushhad Mustuzhar Gilani $\mathbb{D}^{1},{ }^{1}$ Muhammad Tamur Sultan $\mathbb{D D}^{1}{ }^{1}$ Zeng Shuai $\mathbb{D},{ }^{2}$ \\ and Asif Kabir ${ }^{3}$ \\ ${ }^{1}$ University Institute of Information Technology, PMAS-Arid Agriculture University Rawalpindi, Rawalpindi, Pakistan \\ ${ }^{2}$ Department of Communication Engineering, Chongqing University of Posts and Telecommunications, Chongqing, China \\ ${ }^{3}$ University of Kotli, AJK, Pakistan
}

Correspondence should be addressed to Syed Mushhad Mustuzhar Gilani; mushhad@uaar.edu.pk and Zeng Shuai; zengshuai@cqupt.edu.cn

Received 19 November 2019; Revised 13 February 2020; Accepted 17 March 2020; Published 25 April 2020

Academic Editor: María Elena de Cos Gómez

Copyright (c) 2020 Syed Mushhad Mustuzhar Gilani et al. This is an open access article distributed under the Creative Commons Attribution License, which permits unrestricted use, distribution, and reproduction in any medium, provided the original work is properly cited.

\begin{abstract}
This study aimed to explore a metallic striped grid array planar antenna, analyze it numerically in terms of its parameters, and optimize it for best performance. It may be an appropriate candidate for long-range point-to-point connectivity in wireless sensor networks. Antenna gain and frequency impedance bandwidth are two important performance parameters. For an efficient antenna, its gain should be high while maintaining operating bandwidth wide enough to accommodate the entire frequency range for which it has been designed. Concurrently, antenna size should also be small. In this study, antenna dimensions were kept as small as possible without compromising its performance. Its dimensions were $300 \mathrm{~mm} \times 210 \mathrm{~mm} \times 9.9 \mathrm{~mm}$, which made it compact and miniature. It had a maximum gain of $16.72 \mathrm{~dB}$ at $2.45 \mathrm{GHz}$ and maximum frequency impedance bandwidth of $7.68 \%$ relative to $50 \Omega$. It operated across a frequency band ranging from $2.38 \mathrm{GHz}$ to $2.57 \mathrm{GHz}$, encapsulating the entire ISM $2.4 \mathrm{GHz}$ band. Its radiation efficiency remained above $93 \%$ in this band with a maximum of $98.5 \%$ at $2.45 \mathrm{GHz}$. Moreover, it also had narrow HPBWs in horizontal and vertical planes having values of $18.52^{\circ}$ and $31.25^{\circ}$, respectively.
\end{abstract}

\section{Introduction}

Wireless sensor networks usually have to communicate remotely to central monitoring systems. Their placement could be over large geographical area depending upon the intention of their deployment. Sensors that are deployed to monitor air pollution, wildfire detection, landslide detection, water quality monitoring, and natural disaster prevention are often in need to communicate with central monitoring systems wirelessly over long distances. ISM band provides a cost-effective solution for such communication in wireless sensor networks [1].

Our proposed antenna is designed for long-range backhaul connectivity. It can provide connectivity through point-to-point links to many segments of a wireless sensor network spread across a vast area. It can be used to establish communication links between remote research sites, WSNs deployed in mountainous areas and across islands separated by distances up to $10 \mathrm{~km}$, and so forth. It could be a candidate for research and development projects such as Project Loon initiated by Google back in 2013. Project Loon aims to provide communication and Internet connectivity to far furlong areas where commercial infrastructure does not exist. The communication was provided by employing balloons in the stratosphere up to a height of $25 \mathrm{~km}$ from ground. Initially, ISM $2.4 \mathrm{GHz}$ and $5 \mathrm{GHz}$ bands were used for communication purpose. It can be employed with WSNs in volcanic areas to relay information regarding seismic activity to the central monitoring system.

This study aims (i) to evaluate performance constraints of the grid array antenna in terms of gain and frequency impedance bandwidth, (ii) to device a mechanism that could 
reduce consumption of computational resources for future antenna designs, (iii) to propose a long-range antenna design for ISM $2.4 \mathrm{GHz}$ band with characteristics of being lightweight, being easy to fabricate, low cost, being low in complexity, and high performance in terms of impedance bandwidth and gain with narrow beamwidth and high radiation efficiency.

Technologies such as Zigbee and Wi-Fi operating in ISM $2.4 \mathrm{GHz}$ band can be employed as the standard for communication and in clustered wireless sensor networks, a head node responsible for relaying data of all nodes connected to it over long range [2]. Energy conservation is one of the prime objectives of wireless sensor network nodes while maintaining a reliable communication link to other nodes or central system. Directional antennas play a key role in long-range point-to-point communication in wireless sensor networks because they direct electromagnetic energy in narrow beams in particular directions, which not only increases range of communication but also maintains low energy constraints. Grid array antennas are known for their narrow frequency impedance bandwidth [3-6]. Any effort to improve the impedance bandwidth of these antennas can lead to deterioration of other performance parameters such as gain and radiation efficiency. Therefore, optimized antenna design is required, which can operate with maximum performance in terms of all its parameters. Optimization of an antenna needs huge computing resources and time by employing traditional genetic algorithm techniques [7-9]. In this study, the proposed antenna is analyzed numerically first and then optimized for the best performance. Antenna optimization was carried out in parts to overcome the exhaustive computational problems. At first, a parametric analysis was carried out to narrow down ranges of antenna design parameters for which antenna performance was high. These design parameters were the length of transmission line elements and the width of metallic strips. A suitable combination of length and width was chosen after analyzing data obtained from the parametric analysis where gain and frequency impedance bandwidth have high values relative to $-9 \mathrm{~dB}$ value of reflection coefficient $S_{11}$. The reason to choose $-9 \mathrm{~dB}$ threshold of $S_{11}$ for calculation of frequency impedance bandwidth was to find out all those combinations of length and width, where a slight modification in design parameters could lead to maximum frequency impedance bandwidth relative to standard $-10 \mathrm{~dB}$ value of $S_{11}$. After inspection and selection of suitable length and width combination, a modification in the design of antenna was made and further parametric analysis was carried out. In the end, the quasi-Newton algorithm was applied for the finetuning purpose, which is computationally resource-efficient. The use of this strategy not only reduced computation time and resources but also results in a finely optimized antenna in terms of its performance.

\section{Literature Review}

The first grid array design was proposed by J. Kraus in 1964 [10], consisting of a grid of straight wires forming rectangular mesh parallel to a metallic ground plane. Each rectangle of mesh measures one wavelength by one-half wavelength. Broadsides of the mesh act as transmission lines, whereas short sides act as radiators. Current distributions in short sides were in phase with each other producing maximum radiation in a backward angle-fire direction. Frequency impedance bandwidth is affected by the distance between the grid and the ground plane. In 1981, R. Conti proposed the first nontraveling wave microstrip grid array antenna [11]. The antenna had control of aperture illumination, which minimized the side lobes. An analytical model was also developed for equivalent transmission line circuits of wire grids.

The research team of Nakano et al. made several efforts to refine and optimize the grid array antenna further in terms of its performance. In 1994, they analyzed grid array antenna using the method of moment [3], where singularity and perturbation terms were extracted by impedance matrix. Furthermore, an interpolation technique was incorporated to minimize the computation time of the perturbation term. After the numerical analysis of current distribution, it revealed that antenna beam direction was the function of frequency. Also, it was observed that gain decreases when a substrate other than air was used. In 1995, they analyzed a center-fed antenna consisting of two orthogonal layers of grid arrays capable of radiating horizontally and vertically polarized beams [11]. The analysis revealed that the length of short edges should be $0.54 \lambda$ and long edges should be $1.08 \lambda$; also the distance between grid and ground plane should be less than $0.2 \lambda$. In 1998, a meander line grid array antenna was analyzed by using the method of moment (MoM) for area reduction factor [4]; the gain dropped from $21 \mathrm{~dB}$ to $19 \mathrm{~dB}$ for a reduction factor of $38 \%$. The reduction in size also leads to an increase in HPBW in the $H$ plane, while it remained constant in the $E$ plane. A C-figured grid array antenna was proposed to obtain a circularly polarized wave [5]. The antenna structure was analyzed by MoM. C figure elements were placed on both balanced and unbalanced fed grid array antennas separately to obtain circularly polarized waves; after that, reference grid array antennas were compared with C-figured grid array antennas and it was found that gain and HPBW had approximately the same values for both types of antennas. In a comparison of balanced C-figured grid array antenna to unbalanced C-figured antenna, it was found that although HPBW was the same in both cases, bandwidth of unbalanced C-figured grid array antenna was narrower than the balanced C-figured antenna. Further the cross mesh array antennas consisting of two antennas radiating dual linearly polarized and dual circularly polarized waves [12] were studied in 1999. In a similar work, a cross mesh antenna that was a combination of $x$-directed grid arrays and $y$-directed grid arrays having four feed points was proposed in 2001 [13]. The main aim of that research was to study the radiation characteristics of the new cross mesh array antenna. Right and left circular waves were generated separately when $x$-directed and $y$-directed arrays were excited. Right circular waves were generated when $x$ directed grid array was excited through its corresponding feed points. Similarly, left circular waves were generated when $y$-directed grid array was excited through its 
corresponding feed points. In another research, a news impedance matrix element for MoM was formulated to analyze the grid array antenna to reduce computation time as compared to the conventional impedance element [14]. In 2005, a new MoM technique was proposed to obtain current distribution along an arbitrarily shaped wire printed on a dielectric substrate having input impedance matrix elements consisting of single, double, and triple integrals conventionally [6]. The newly formulated input impedance matrices for two antennas, i.e., meander loop and grid array antennas, were analyzed and results were compared with the conventional impedance matrix element. Results showed that computation time was drastically reduced by a factor of 231 for meander loop antenna and 937 for the grid array antenna due to the new MoM technique. A two-layer rear space strip type grid array antenna using the finite difference time domain method was analyzed in 2006 [15]. Antenna rear space consists of two layers. On top, there was a layer of the substrate and, below that, there was a layer of air above the ground plane of the antenna. Antenna beam was narrow with small side lobes. It had a maximum directivity of $18 \mathrm{~dB}$ at $7 \mathrm{GHz}$ with VSWR bandwidth of $13 \%$. In 2007, a modified grid array antenna consisting of loop structure radiation elements was designed, which radiated circularly polarized waves [16]. It was a low-profile antenna with the frequency bandwidth of $2.3 \%$ and a maximum gain of $15 \mathrm{~dB}$. The gain and direction of the beam of grid array antenna varied with frequency. As the frequency decreased the gain also decreased and vice versa. With an increase in radius of the loop frequency response curve shifted the radiation beams to lower frequency region. The antenna was consisting of 27 loops having a gain of $20 \mathrm{dBi}$.

As already discussed, a grid array antenna has narrow frequency impedance bandwidth and its input impedance is always greater than $50 \Omega$. Even the voltage standing wave ratio (VSWR) bandwidths in the cases of $[3,6]$ were $1.5 \%$ and $2.6 \%$ relative to an input impedance of $55 \Omega$ and $160 \Omega$,, respectively. So, it is important to increase frequency impedance bandwidth while keeping input impedance near $50 \Omega$ of an antenna.

In 2008, Chen et al. optimized a microstrip grid array antenna using a parallel genetic algorithm [7]. At $2.45 \mathrm{GHz}$, antenna had a maximum gain of $18.3 \mathrm{~dB}$, while its VSWR bandwidth was equal to $4.5 \%$ relative to $50 \Omega$. Radiating elements of the antenna were 13 similar to those of [15]. But an increase in the number of radiating elements also leads to an increase in antenna size. In 2010 [8], they proposed a novel antenna consisting of elliptical radiation elements and sinusoidal shaped transmission lines. The advantage of such an approach was that elliptical radiation elements improved frequency impedance bandwidth, while the use of sinusoidal transmission lines reduced the antenna size. The antenna was optimized using the genetic algorithm in combination with the finite difference in time-domain method. It took 110 hours on a cluster system to optimize. After optimization at $2.45 \mathrm{GHz}$, antenna had a maximum gain of $13.7 \mathrm{~dB}$ with 25\% frequency impedance bandwidth. In 2013, they modified this antenna by using a linearly tapered ground plane and optimized it [9]. After optimization at $5.8 \mathrm{GHz}$, antenna had a maximum gain of $15.1 \mathrm{~dB}$ with frequency impedance bandwidth of $25.6 \%$. Again, the optimization process takes 112 hours on a cluster system. In $[8,9]$, optimization of antenna took too much time and resources. So, a technique was required which took low computational resources and time to optimize antenna design for best performance.

\section{Design of Proposed Antenna}

The antenna with dimensions of $A \times B$ (i.e., $300 \mathrm{~mm} \times 210 \mathrm{~mm}$ ) was designed, which had a structure of an ordinary grid array antenna as shown in Figure 1. The long side of a rectangular frame whose length was " $L$ " acted as transmission line, while short side whose length was " $S$ " acted as a radiator. The numbers of transmission lines and radiators were 8 each. The distance of the ground plane from the metallic grid was " $H$." The antenna was fed by coaxial cable via SMA connector. The substrate between the antenna and the ground plane was air. The width of the metallic strip was " $W$," while the thickness of the strip was fixed to $0.5 \mathrm{~mm}$. Ansys HFSS (ANSYS Inc., Canonsburg, PA, USA) with an integral equation method was used to analyze the antenna parametrically for frequency impedance bandwidth and gain at frequency of $2.45 \mathrm{GHz}$.

\section{Parametric Analysis}

In the first stage of parametric analysis, antenna was analyzed to find out a combination of " $L$ " and " $W$ " at which it had high values of gain and frequency impedance bandwidth. Initially, values of " $S$ " and " $H$ " were kept fixed at $S=0.5 \lambda$ and $H=0.08 \lambda$, respectively, while values of " $L$ " and " $W$ " were varied from $0.75 \lambda$ to $1.25 \lambda$ and from $0.01 \lambda$ to $0.1 \lambda$, respectively, with an interval of $0.005 \lambda$. Frequencies at which analysis was carried out were ranged from $2.4 \mathrm{GHz}$ to $2.5 \mathrm{GHz}$ with an interval of $0.01 \mathrm{GHz}$ (i.e., total 11 in numbers). After parametric analysis, further investigation was carried out on obtained data to find out all those combinations of " $L$ " and " $W$," where gain and frequency impedance bandwidth had high values. There were many combinations of " $L$ " and " $W$," where antenna resonated two or more times on the entire frequency range. In between those resonances at some frequency range, it had values of the reflection coefficient $S_{11}$ slightly greater than that of $-10 \mathrm{~dB}$ due to which it had narrow frequency impedance bandwidth. A slight modification in antenna design and optimization could fix that problem as it will be explained in the next sections of this article. So, after careful inspection of parametric data, all those combinations of " $L$ " and " $W$ " were separated, for which a minimum of 9 or more sampling frequencies out of 11 had $S_{11}$ values less than $-10 \mathrm{~dB}$. Those values of " $L$ " and " $W$ " are presented in Table 1 with corresponding $S_{11}$, gain, and frequency impedance bandwidth values against frequency range from $2.4 \mathrm{GHz}$ to $2.5 \mathrm{GHz}$ with an interval of $0.01 \mathrm{GHz}$.

Then, to identify all combinations of " $L$ " and " $W$," where values of $S_{11}$ were slightly higher than $-10 \mathrm{~dB}$ on the entire frequency range, the threshold level of $S_{11}$ was increased to 


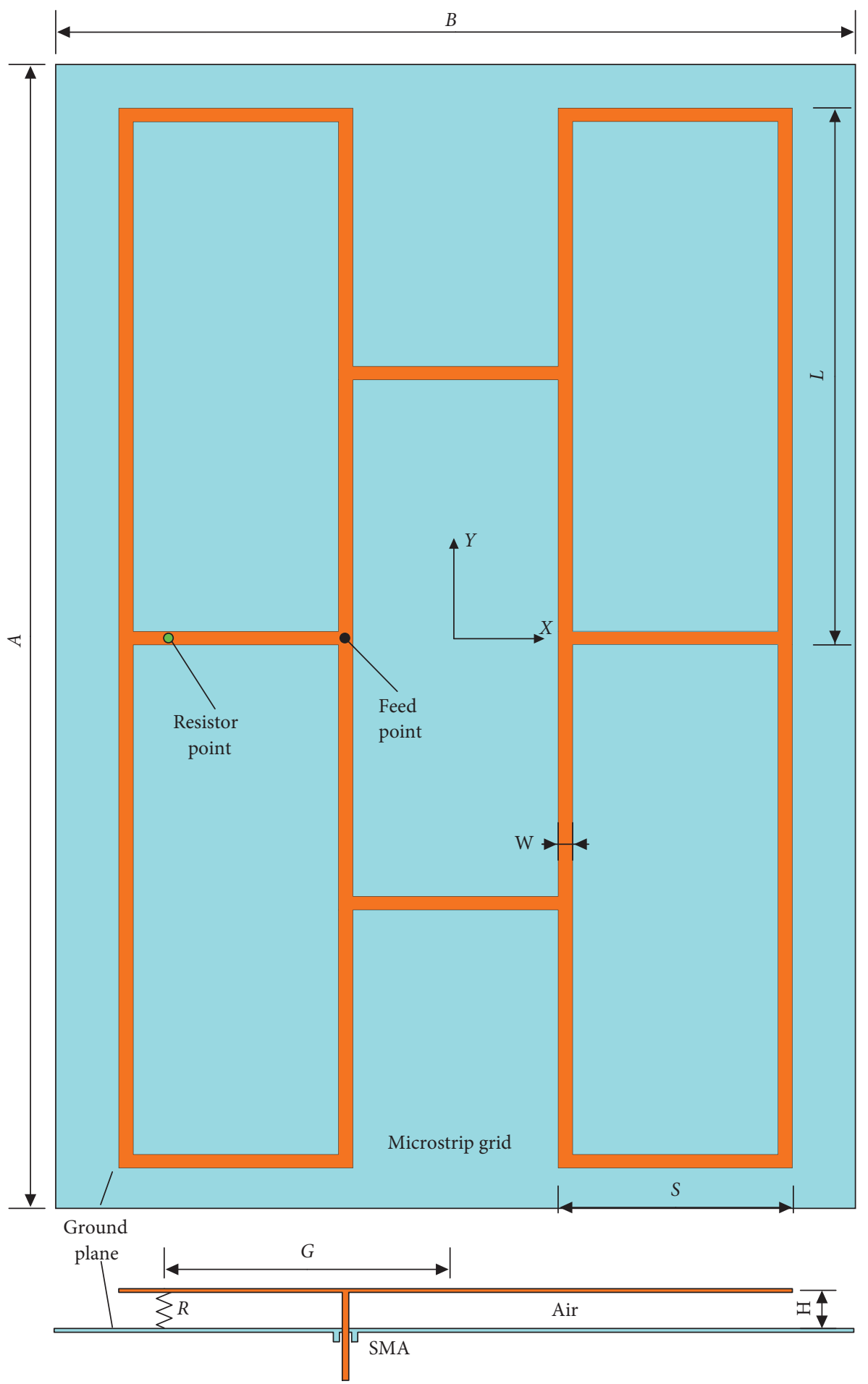

Figure 1: Proposed antenna design.

$-9 \mathrm{~dB}$ and new frequency impedance bandwidths were determined. These new frequency impedance bandwidths are presented in Table 1. All the above processes narrowed down values of antenna design parameters " $L$ " and " $W$ " for its maximum performance in terms of frequency impedance bandwidth and gain.

From Table 1, it can be observed that, at $L=140.7625 \mathrm{~mm}$ and $W=3.6750 \mathrm{~mm}$, frequency impedance bandwidth has a maximum value of $4.08 \%$ relative to $-9 \mathrm{~dB}$ threshold of $S_{11}$, which covers entire ISM, $2.4 \mathrm{GHz}$ band. Gain is also maximum at this combination of " $L$ " and " $W$ " having a value of $-16.92 \mathrm{~dB}$. If this combination was chosen for further optimization of the antenna, then there was a possibility of missing some combinations of " $L$ " and " $W$ " present in original parametric analysis data at which the value of $S_{11}$ is also less than $-9 \mathrm{~dB}$ against each frequency from $2.4 \mathrm{GHz}$ to $2.5 \mathrm{GHz}$. Those 
TABLE 1: Combinations of length and width having 9 or more values of frequencies at which $S_{11} \leq-10 \mathrm{~dB}$.

\begin{tabular}{|c|c|c|c|c|c|c|c|c|}
\hline \multirow[b]{2}{*}{$\begin{array}{l}\text { Frequency } \\
(\mathrm{GHz})\end{array}$} & \multicolumn{8}{|c|}{$\mathrm{S}_{11}(\mathrm{~dB})$} \\
\hline & $\begin{array}{c}L=135.8625 \\
\text { and } \\
W=2.4500 \\
(\mathrm{~mm})\end{array}$ & $\begin{array}{c}L=137.0875 \\
\text { and } \\
W=2.4500 \\
(\mathrm{~mm})\end{array}$ & $\begin{array}{c}L=137.0875 \\
\text { and } \\
W=3.0625 \\
(\mathrm{~mm})\end{array}$ & $\begin{array}{c}L=137.7000 \\
\text { and } \\
W=3.0625 \\
(\mathrm{~mm})\end{array}$ & $\begin{array}{c}L=138.3125 \\
\text { and } \\
W=3.6750 \\
(\mathrm{~mm})\end{array}$ & $\begin{array}{c}L=138.925 \\
\text { and } \\
W=3.0625 \\
(\mathrm{~mm})\end{array}$ & $\begin{array}{c}L=138.925 \\
\quad \text { and } \\
W=3.6750 \\
(\mathrm{~mm})\end{array}$ & $\begin{array}{c}L=140.7625 \\
\text { and } \\
W=3.6750 \\
(\mathrm{~mm})\end{array}$ \\
\hline 2.40 & -6.0547 & -20.0428 & -7.7774 & -12.6340 & -6.6268 & -20.3372 & -7.6345 & -17.6077 \\
\hline 2.41 & -8.3277 & -21.2642 & -10.7495 & -20.8480 & -8.7941 & -23.1618 & -10.5209 & -34.0153 \\
\hline 2.42 & -12.2417 & -12.5088 & -16.2745 & -16.1391 & -12.4298 & -13.5948 & -15.9357 & -15.3920 \\
\hline 2.43 & -17.2961 & -10.2786 & -34.0478 & -10.2547 & -20.2624 & -10.6048 & -30.6464 & -10.8323 \\
\hline 2.44 & -13.4937 & -11.9863 & -17.5265 & -7.9971 & -24.4649 & -10.7131 & -16.3949 & -9.7477 \\
\hline 2.45 & -10.7989 & -19.2861 & -12.5767 & -8.0401 & -14.0835 & -14.8016 & -11.2576 & -9.3720 \\
\hline 2.46 & -12.2086 & -25.2664 & -10.9056 & -10.0502 & -10.7083 & -34.4384 & -9.4284 & -10.3894 \\
\hline 2.47 & -17.8304 & -15.0133 & -11.4929 & -14.6577 & -10.6537 & -15.6824 & -10.1338 & -16.0945 \\
\hline 2.48 & -24.9997 & -10.3702 & -17.3352 & -29.0724 & -14.6946 & -10.3307 & -14.6155 & -29.9700 \\
\hline 2.49 & -15.3060 & -7.7319 & -20.0749 & -18.5807 & -24.7967 & -7.6640 & -38.9414 & -14.5070 \\
\hline 2.50 & -10.7191 & -6.1039 & -12.2289 & -11.7554 & -15.2281 & -6.0429 & -15.7013 & -10.2916 \\
\hline Gain $(\mathrm{dB})$ & 13.19 & 10.37 & 12.64 & 9.20 & 13.82 & 9.56 & 12.81 & 16.92 \\
\hline $\begin{array}{l}\text { Frequency } \\
\text { impedance } \\
\text { bandwidth (\%) }\end{array}$ & 3.25 & 3.28 & 3.67 & 1.61 & 3.25 & 3.28 & 1.21 & 1.61 \\
\hline $\begin{array}{l}\text { Frequency } \\
\text { impedance } \\
\text { bandwidth } \\
\text { relative to } \\
S_{11} \leq-9 \mathrm{~dB}(\%)\end{array}$ & 3.25 & 3.28 & 3.67 & 1.61 & 3.25 & 3.28 & 3.67 & 4.08 \\
\hline
\end{tabular}

combinations of " $L$ " and " $W$ " could also be an equal candidate for further optimization of antenna provided gain was sufficiently high. So, frequency impedance bandwidth was plotted for $-9 \mathrm{~dB}$ threshold of $S_{11}$ to verify the existence of any other combination of " $L$ " and " $W$ " at which impedance bandwidth has a maximum value.

Figures 2(a) and 2(b) show the results of simulated frequency impedance bandwidth. These results were calculated while keeping the $S_{11}$ threshold value $-9 \mathrm{~dB}$ relative to $50 \Omega$. Frequency impedance bandwidth is determined by the following formula:

$$
\begin{aligned}
\text { FIBW } & =\frac{f_{\text {max }}-f_{\text {min }}}{f_{\text {mean }}}, \\
f_{\text {mean }} & =\frac{f_{\text {max }}+f_{\text {min }}}{2},
\end{aligned}
$$

where $f_{\max }$ and $f_{\min }$ are maximum and minimum frequencies between which values of $S_{11}$ remained less than or equal to $-9 \mathrm{~dB}$.

Figure 2(a) presents a relationship between frequency impedance bandwidth and length and width of radiation elements after first parametric analysis. Frequency impedance bandwidths were set to zero for all those combinations of " $L$ " and " $W$," where antenna did not resonate on the entire frequency range because at those combinations frequency impedance bandwidth cannot be determined. From Figures 2(b) and 2(c), it can be observed that maximum bandwidth is laying around $L=0.87 \lambda$ and $W=0.03 \lambda$; that is, $L=140.7625 \mathrm{~mm}$ and $W=3.6750 \mathrm{~mm}$, respectively. So, the antenna has maximum frequency impedance bandwidth on this combination of " $L$ " and " $W$."
Similarly, Figure 3(a) represents the variation of reflection coefficient $S_{11}$ for " $L$ " and " $W$." Figures 3(b) and 3(c) represent the reflection coefficient parameter $S_{11}$ concerning $50 \Omega$ reference impedance against " $L$ " and " $W$," respectively. Values of $S_{11}$ for all those combinations of " $L$ " and " $W$ " for which antenna did not resonate for the entire frequency range were set to zero. The majority of minimum values of $S_{11}$ lie between $L=136 \mathrm{~mm}$ and $146 \mathrm{~mm}$ and between $W=2.4 \mathrm{~mm}$ and $8.6 \mathrm{~mm}$.

Simulated gain with respect to " $L$ " and " $W$ " is shown in Figures 4(a) and separately in Figures 4(b) and 4(c) against variations of " $L$ " and " $W$," respectively. It can be noted that maximum gain of $16.92 \mathrm{~dB}$ is also around $L=0.87 \lambda$ and $W=0.03 \lambda$, that is, at $L=140.7625 \mathrm{~mm}$ and $W=3.6750 \mathrm{~mm}$, respectively.

So, from the above discussion, it can be concluded that antenna has maximum gain and frequency impedance bandwidth around $L=0.87 \lambda$ and $W=0.03 \lambda$ (i.e., at $L=140.7625 \mathrm{~mm}$ and $W=3.6750 \mathrm{~mm}$ ). But, to meet the standard, antenna frequency impedance bandwidth should be maximum against $-10 \mathrm{~dB}$ threshold value of $S_{11}$. At $L=140.7625 \mathrm{~mm}$ and $W=3.6750 \mathrm{~mm}$, antenna resonated two times around $2.41 \mathrm{GHz}$ and $2.48 \mathrm{GHz}$. Values of $S_{11}$ were less than $-10 \mathrm{~dB}$ for the entire ISM band except for $2.44 \mathrm{GHz}$ to $2.46 \mathrm{GHz}$, where they were slightly higher than $-10 \mathrm{~dB}$, that is, between $-9.75 \mathrm{~dB}$ and $-9.37 \mathrm{~dB}$, as shown in Figure 5 . So, bandwidth was narrow for both resonances. To expand frequency impedance bandwidth relative to $-10 \mathrm{~dB}$ of $S_{11}$, a modification in antenna design was made by introducing a resistor " $\mathrm{R}$ " to connect the metallic grid and ground plane electrically. The resistor reduces antenna input impedance, which increases in frequency impedance bandwidth [17]. 


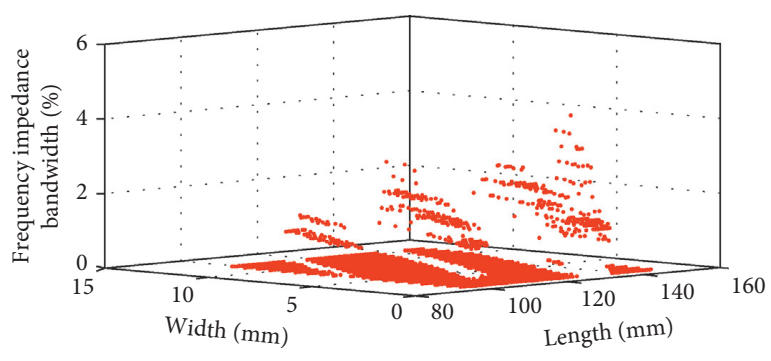

(a)

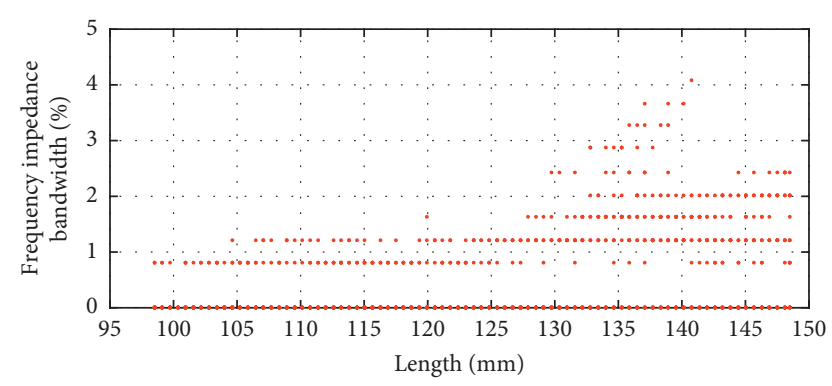

(b)

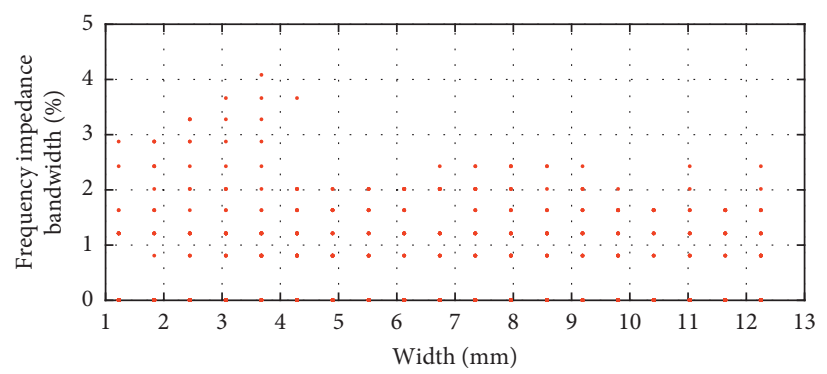

(c)

FIGURE 2: (a) Frequency impedance bandwidth versus " $L$ ” and " $W$." (b) Frequency impedance bandwidth versus " $L . "$ (c) Frequency impedance bandwidth versus " $W$.".

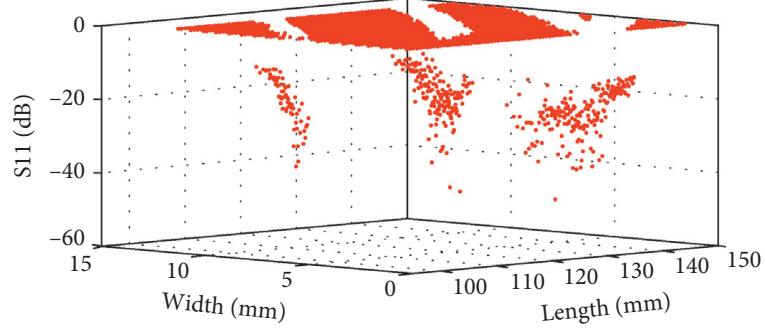

(a)

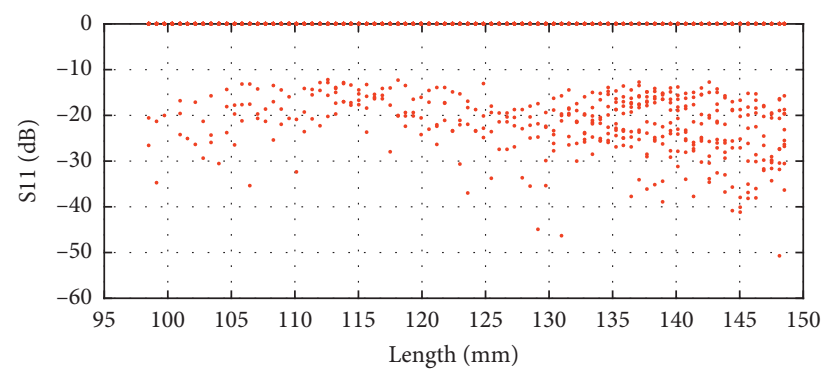

(b)

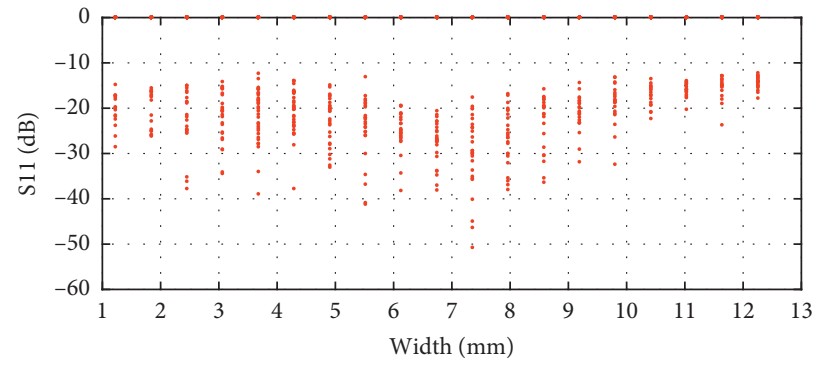

(c)

Figure 3: (a) Reflection coefficient $S_{11}$ versus " $L$ ” and “ $W$ "; (b) $S_{11}$ versus " $L$ "; (c) $S_{11}$ versus " $W$.".

The introduction of the resistor also increases ohmic losses of the antenna, which may lead to a decrease in antenna radiation efficiency and its gain. Proper placement of the resistor was necessary to estimate its effects on frequency impedance bandwidth and gain of the antenna at $2.45 \mathrm{GHz}$. Again, Ansys HFSS with the IE method was used to parametrically analyze the antenna in the second stage. This time parametric values of $S=0.5 \lambda, H=0.08 \lambda, L=0.87 \lambda$, and $W=0.03 \lambda$ were fixed. The dimensions $G$ and $R$ were varied from $0.25 \lambda$ to $0.67 \lambda$ and from $1 \Omega$ to $50 \Omega$ with an interval of $0.01 \lambda$ and $1 \Omega$, respectively.

Simulated frequency impedance bandwidths against $G$ and resistance $R$ are shown in Figure 6(a) and separately in Figures 6(b) and 6(c), respectively. For all those 


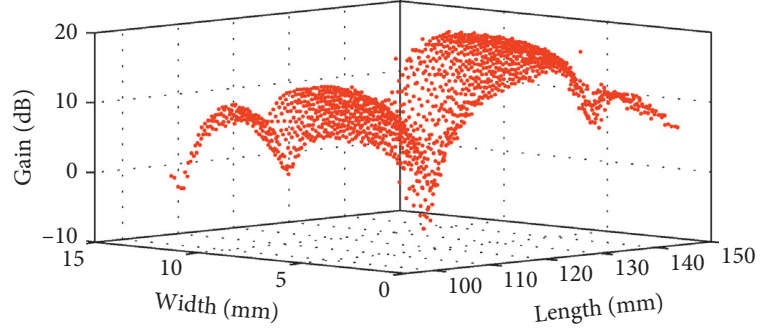

(a)

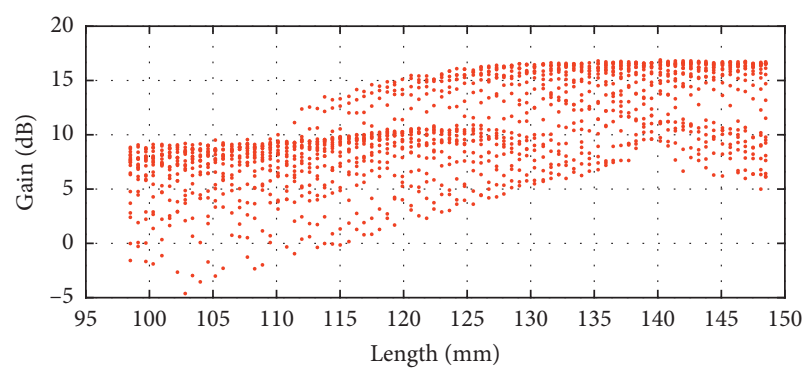

(b)

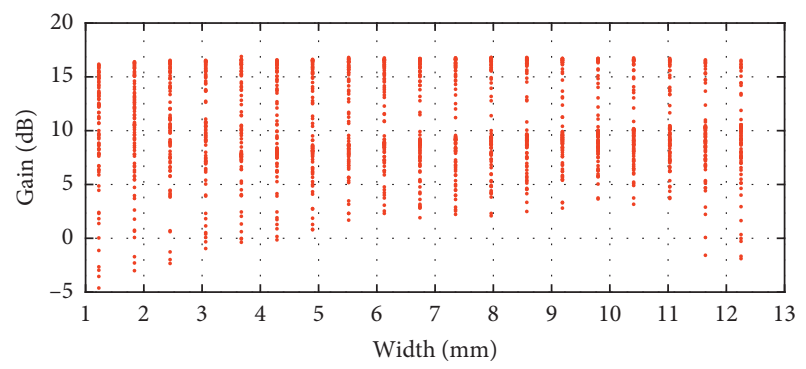

(c)

Figure 4: (a) Gain versus "L" and “W." (b) Gain versus "L.” (c) Gain versus "W.”.

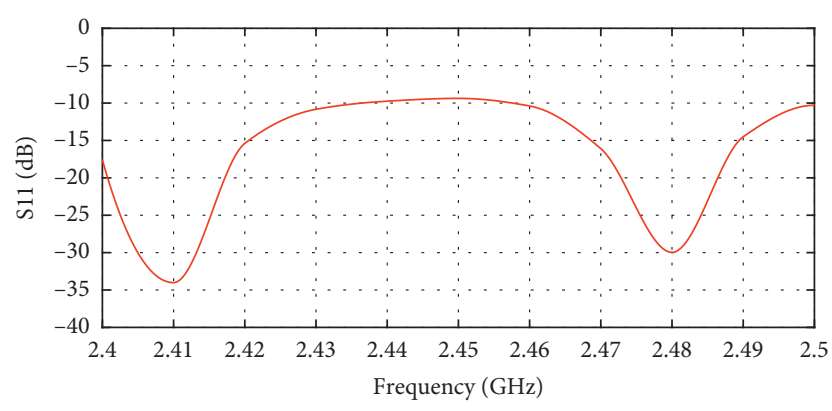

Figure 5: Reflection coefficient versus frequency.

combinations of $G$ and $R$ for which antenna did not resonate, frequency impedance bandwidth was set to zero. It can be observed that the highest values of bandwidth occur between $G=55 \mathrm{~mm}$ and $75 \mathrm{~mm}$ and between $R=35 \Omega$ and $45 \Omega$. The antenna has maximum frequency impedance bandwidth at $G=74.7250 \mathrm{~mm}$ and $R=40 \Omega$ to $41 \Omega$ having a value of $5.67 \%$ which covers whole ISM, $2.4 \mathrm{GHz}$ band.

Figures $7(\mathrm{a})-7$ (c) depict the reflection coefficient $S_{11}$ concerning reference impedance of $50 \Omega$ against parameters $G$ and $R$, respectively. Again, values of $S_{11}$ for all those combinations of $G$ and $R$, where antenna did not resonate on the entire frequency range, were set to zero. It can also be noted that $S_{11}$ has the lowest values between $G=55 \mathrm{~mm}$ and $75 \mathrm{~mm}$ and between $R=35 \Omega$ and $45 \Omega$ with a minimum value at $G=74.7250 \mathrm{~mm}$ and $R=41 \Omega$.

The gain of the antenna at frequency of $2.45 \mathrm{GHz}$ is shown in Figures 8(a)-8(c). Variation in resistor $R$ value has almost no effect on it as demonstrated in Figure 8(b), but it gradually increased with an increase in the value of $G$, as shown in Figure $8(\mathrm{a})$. At $G=74.7250 \mathrm{~mm}$ and $R=41 \Omega$ it has maximum value of $16.74 \mathrm{~dB}$.
After the second stage of parametric analysis, the value of the reflection coefficient parameter $S_{11}$ remained less than $-10 \mathrm{~dB}$ for the entire ISM $2.4 \mathrm{GHz}$ band at $G=0.61 \lambda$ (i.e., at $74.7250 \mathrm{~mm}$ ) and $R=41 \Omega$ as shown in Figure 9. However, it had a value of approximately $-10 \mathrm{~dB}$ at $2.40 \mathrm{GHz}$, which limits frequency impedance bandwidth beyond $2.40 \mathrm{GHz}$. To further enhance the impedance bandwidth, a light optimization was carried out so that antenna can operate in the ISM $2.4 \mathrm{GHz}$ band and beyond.

\section{Antenna Optimization}

For optimization of antenna, again Ansys HFSS was used, where the quasi-Newton algorithm with IE methodology was applied. The antenna was fed with a coaxial cable at wave port. The material between antenna and ground plane was considered as air. Metallic grid and ground plane were assumed to be made of copper sheets of finite conductivity of $5.8 \times 107 \mathrm{~S} / \mathrm{m}$ and $0.5 \mathrm{~mm}$ thickness.

Only $H=0.8 \lambda$ was fixed; all other parameters were made variable with fixed antenna size of $A \times$ $B=300 \mathrm{~mm} \times 210 \mathrm{~mm}$. Maximization of antenna gain and reflection coefficient $S_{11} \leq-10 \mathrm{~dB}$ for the entire ISM $2.4 \mathrm{GHz}$ band were constituents of the fitness function. Initially variables had values $S=0.5 \lambda, L=0.87 \lambda, W=0.03 \lambda, G=0.61 \lambda$, and $R=41 \Omega$. The solution was obtained after approximately 18 minutes at $11^{\text {th }}$ iteration on a computer system with 8 cores and $32 \mathrm{~GB}$ of RAM. The process of optimization consumed $15 \mathrm{MB}$ of RAM only. After optimization, optimum values of parameters were $S=61.25 \mathrm{~mm}, W=3.68 \mathrm{~mm}$, $L=140.77 \mathrm{~mm}, G=74.73 \mathrm{~mm}$, and $R=41.5 \Omega$. Reflection coefficient $S_{11}$ for frequency is shown in Figure 10. The optimized antenna operates well beyond the ISM $2.4 \mathrm{GHz}$ range, i.e., between $2.385 \mathrm{GHz}$ and $2.565 \mathrm{GHz}$, covering the 

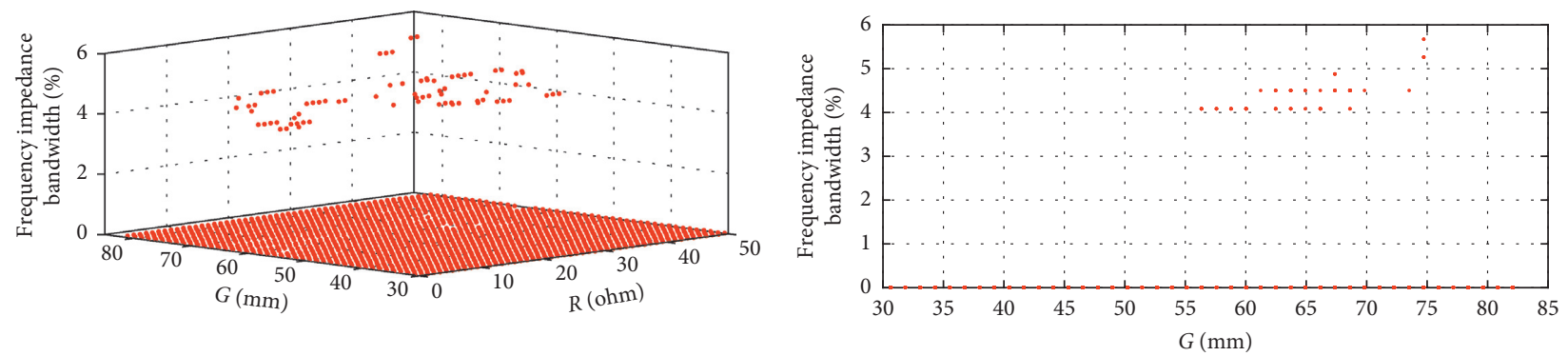

(a)

(b)

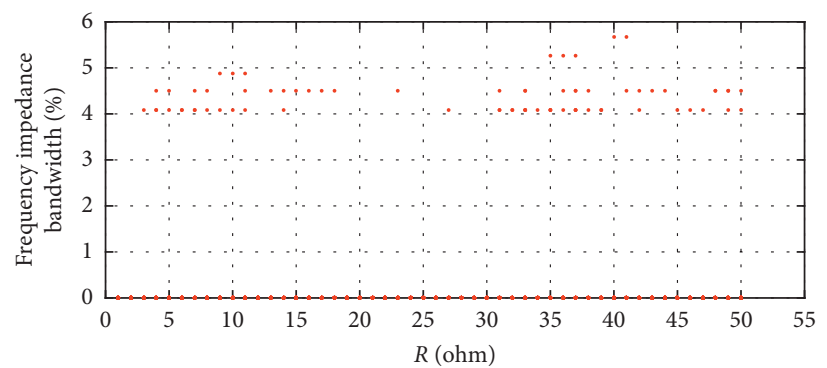

(c)

Figure 6: (a) Frequency impedance bandwidth versus “ $G$ ” and " $R$.” (b) Frequency impedance bandwidth versus " $G$." (c) Frequency impedance bandwidth versus " $R$.".

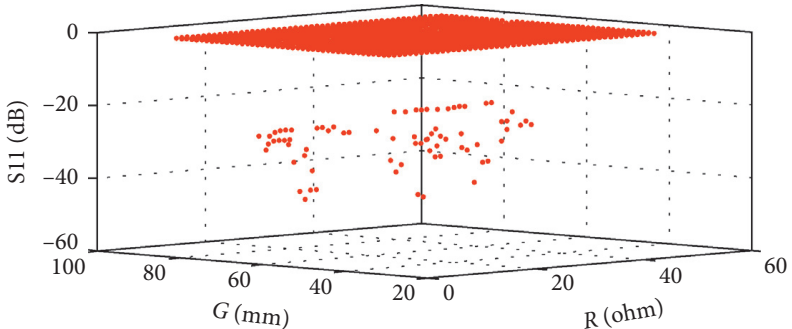

(a)

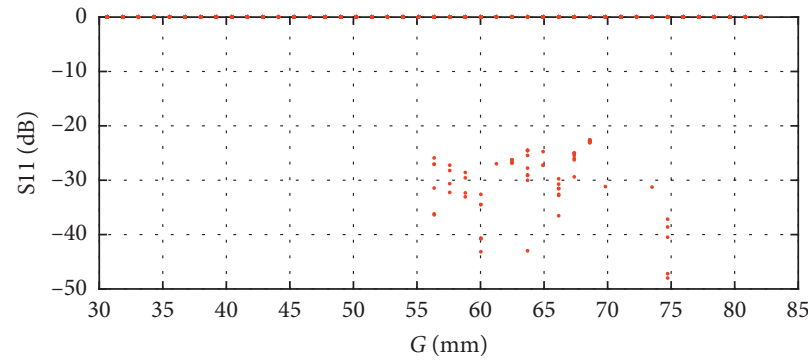

(b)

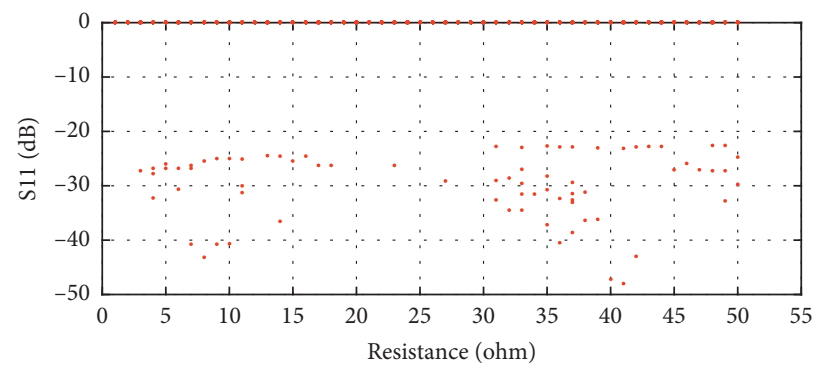

(c)

Figure 7: Reflection coefficient $S_{11}$ : (a) $S_{11}$ versus “G”; (b) $S_{11}$ versus "R.”.

entire ISM band with frequency impedance bandwidth of $7.27 \%$ as shown in Figure 10.

At $2.45 \mathrm{GHz}$, total gain was $16.72 \mathrm{~dB}$ in $z x$-plane and $z y$ plane, while half power beamwidth (HPBW) in these planes was $18.52^{\circ}$ and $31.25^{\circ}$, respectively, as illustrated in Figures 11(a) and 11(b). These measurements of HPBW indicate that antenna has narrow beamwidth with high power and therefore it is less prone to interference.

Antenna radiation pattern indicates its narrow beam, as shown in Figure 12.

\section{Results and Discussion}

Antenna gain can be enhanced by increasing the number of radiation elements in it, but it causes an increase in its size as well. In our proposed antenna design, the number of radiation elements is 8 , i.e., one more than $[8,9]$. But an increase in the number of radiation elements did not affect its size; instead, it remained compact. After optimization, the maximum gain of the antenna at $2.45 \mathrm{GHz}$ was $16.72 \mathrm{~dB}$ with a frequency impedance bandwidth of $7.68 \%$. 


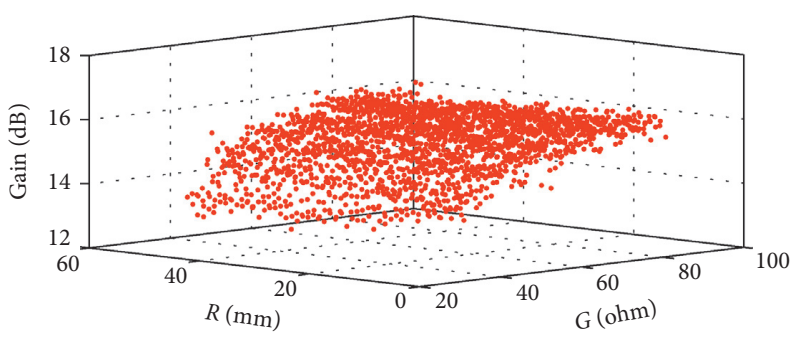

(a)

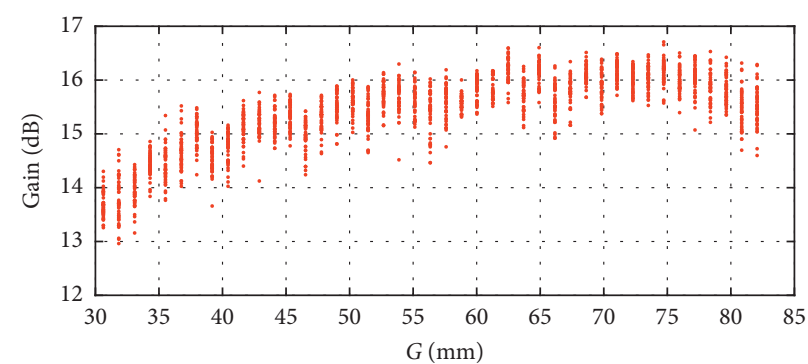

(b)

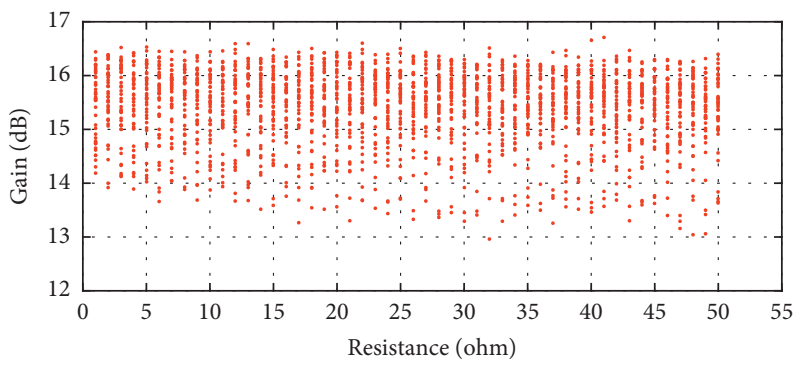

(c)

Figure 8: Gain versus " $G$ ” and " $R$ ”: (a) gain versus “ $G$ ”; (b) gain versus " $R$. ."

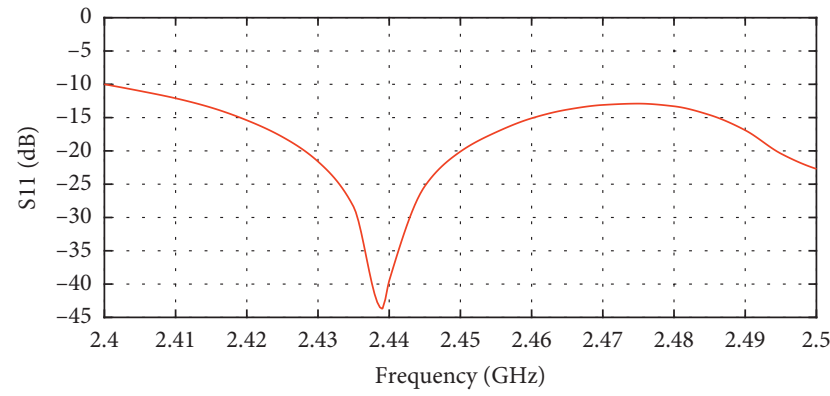

Figure 9: Reflection coefficient after second parametric analysis.

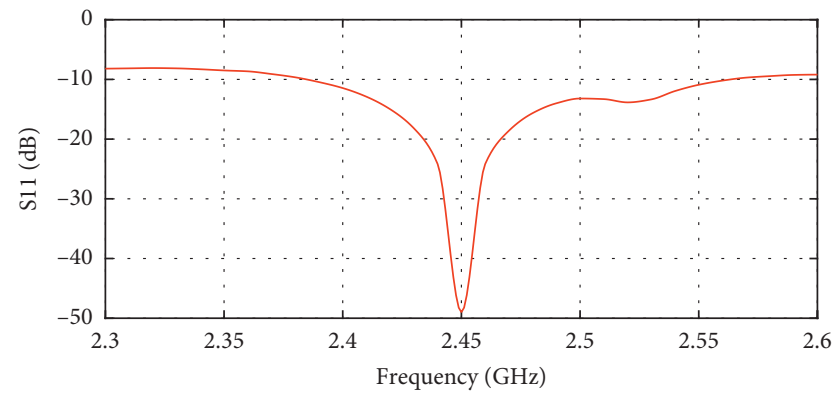

FIgURE 10: Reflection coefficient after optimization.

Meanwhile, antenna radiation efficiency remained above $93 \%$ with a maximum value of $98.54 \%$ at $2.45 \mathrm{GHz}$. HPBW of the antenna was $31.25^{\circ}$ and $18.52^{\circ}$ in horizontal and vertical planes, respectively. Table 2 presents a performance comparison of our proposed antenna with previous works.

\section{Antenna Operational Principle}

Figure 13 shows the current distribution along transmission lines and radiation elements of the antenna at $2.45 \mathrm{GHz}$.

At this frequency, the antenna has maximum gain and radiation efficiency values because currents are concentrated mainly along with seven radiation elements represented by black vectors, where they are added in phase and result in radiation pattern, while in transmission lines currents are mutually exclusive and opposite in direction in terms of far field as shown by white vectors. So, seven radiation elements act as dipole and generate radiation patterns. Gain and radiation efficiency both tend to decline at frequencies less or greater than $2.45 \mathrm{GHz}$ because of an increase in the misalignment of current vectors along with radiation elements at these frequencies.

\section{Radiation Efficiency}

Antenna radiation efficiency against frequency is depicted in Figure 14 , which is $98.54 \%$ at $2.45 \mathrm{GHz}$, while it remained above $93 \%$ for the entire ISM $2.4 \mathrm{GHz}$ band.

\section{Gain}

The gain of antenna remained high for the entire ISM $2.4 \mathrm{GHz}$ range with a maximum of $16.72 \mathrm{~dB}$ at $2.45 \mathrm{GHz}$, as shown in Figure 15. It reduced as wavelength increased because the distance between the ground plane and the grid is dependent on wavelength and antenna gain is sensitive to this distance [19] but even then it remained above $14.7 \mathrm{~dB}$ at $2.5 \mathrm{GHz}$. Reduction in the gain of $2 \mathrm{~dB}$ is in acceptable range because it is less than $3 \mathrm{~dB}$, which is standard for communication links. 


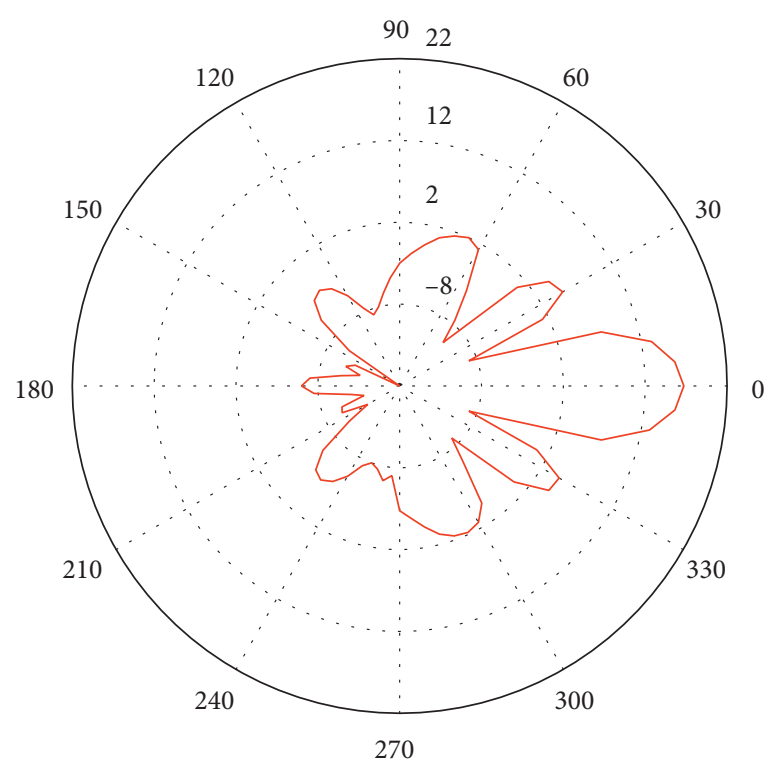

(a)

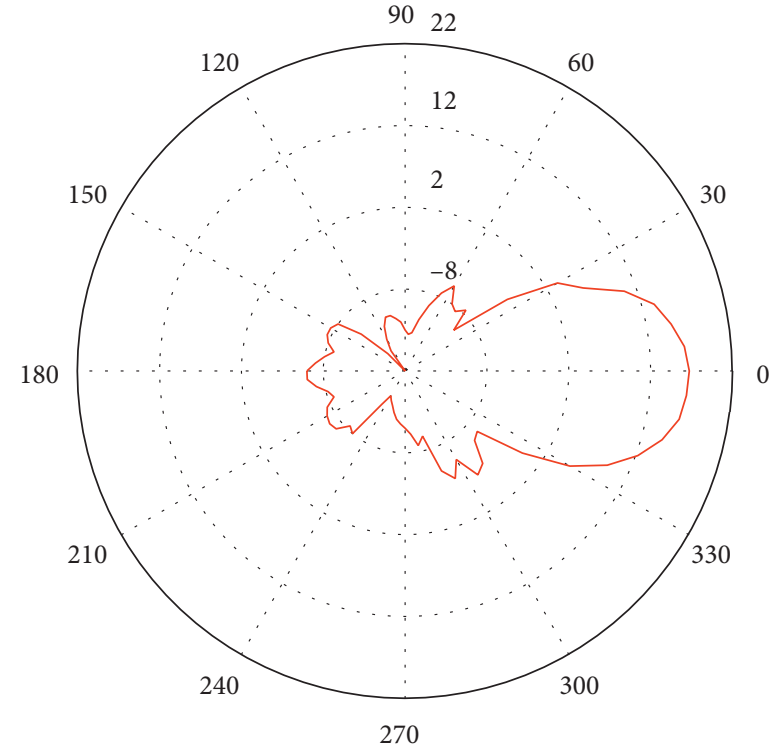

(b)

Figure 11: Gain and HPBW: (a) in $z x$-plane; (b) in $z y$-plane.

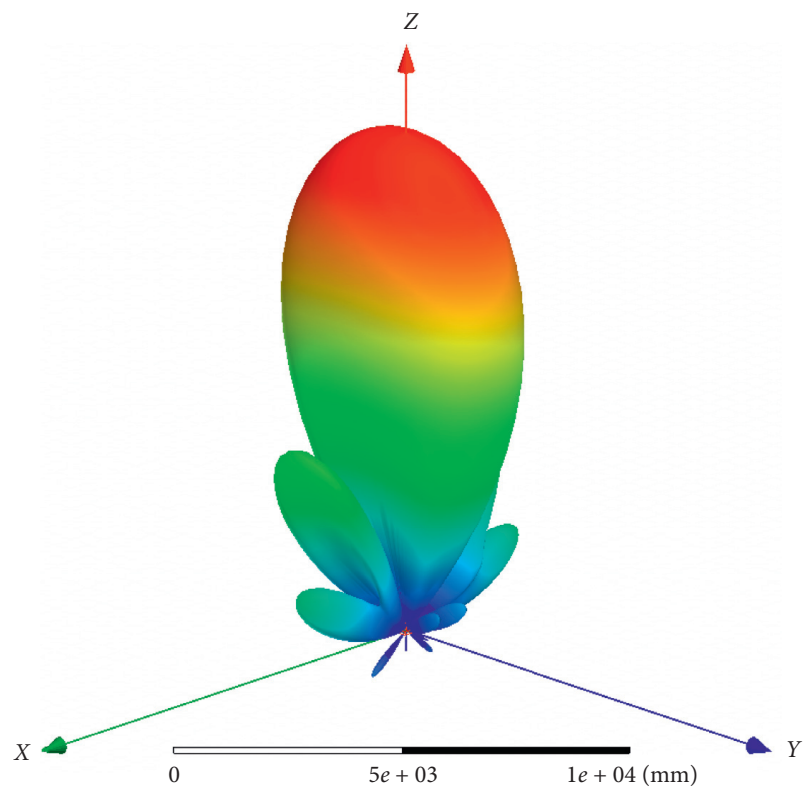

FIGURE 12: Radiation pattern.

\section{Half Power Beam Width (HPBW)}

HPBW of the antenna is depicted in Figure 16 where it can be seen that in $z x$-plane HPBW varied from $18^{\circ}$ to $19^{\circ}$ for the entire frequency range. Similarly, it varied from $30.75^{\circ}$ to $31.75^{\circ}$ in $z y$-plane.

\section{Antenna Fabrication}

Antenna grid array frame and the ground plane were fabricated by a sheet of copper of $0.5 \mathrm{~mm}$ thickness. The optical laser cutting technique was used to cut the grid array frame according to measurement. The frame was raised by ground plane by Teflon pieces having a height equal to that of substrate, that is, $9.9 \mathrm{~mm}$. Figures $17(\mathrm{a})-17$ (c) give front, side, and back views of antenna, respectively.

Measurements of antenna gain and reflection coefficient $S_{11}$ were carried out. From $S_{11}$ measurement, it can be observed that antenna operates between $2.39 \mathrm{GHz}$ and $2.57 \mathrm{GHz}$ having frequency impedance bandwidth of $7.65 \%$. $S_{11}$ plot against frequency range from $2.3 \mathrm{GHz}$ to $2.6 \mathrm{GHz}$ is shown in Figure 18.

\section{Link Budget Calculation}

To estimate the potential range and performance of the proposed antenna over the long range, the link budget is calculated for it. According to [20], power received by a receiver at a distance " $D$ " $(\mathrm{Km})$ at frequency " $F$ " $(\mathrm{GHz})$ is estimated by the formula

$$
P_{r}=P_{t}+G_{t}+G_{r}-L_{\mathrm{fs}}-L
$$

where $P_{r}$ is the received power in $\mathrm{dBm}$ and $P_{\mathrm{t}}$ is the transmitted power in $\mathrm{dBm}$. $G_{\mathrm{t}}$ is the gain of transmitter antenna in $\mathrm{dB} . G_{\mathrm{r}}$ is the gain of receiver antenna in $\mathrm{dB}, \mathrm{L}_{\mathrm{fs}}$ is free space loss in $\mathrm{dB}$, and $L$ is combined loss due to connectors and cables on both transmitter and receiver side, which is also measured in $\mathrm{dB}$. In equation (2) $P_{\mathrm{t}}, G_{\mathrm{r}}$, and $G_{\mathrm{t}}$ are straight values, while $\mathrm{L}_{\mathrm{fs}}$ and $L$ are combinations of different parameters. $\mathrm{L}_{\mathrm{fs}}$ can be defined as

$$
L_{\mathrm{fs}}=20 \log _{10} D+20 \log _{10} F+92.45 \text {. }
$$

Similarly, $L$ of equation (2) is a combination of cable losses plus connector losses on both transmitter and receiver sides. So,

$$
L=2 L_{\text {cable }}+4 L_{\text {connector }} \text {. }
$$

$L_{\text {cable }}$ is loss due to cable measured in $\mathrm{dB}$. For the computational purpose, we have taken LMR600 cable having 
Table 2: Performance comparison.

\begin{tabular}{|c|c|c|c|c|c|c|c|c|}
\hline $\begin{array}{l}\text { Research } \\
\text { work }\end{array}$ & $\begin{array}{c}\text { Operating } \\
\text { frequency } \\
(\mathrm{GHz})\end{array}$ & $\begin{array}{c}\text { Frequency } \\
\text { impedance } \\
\text { bandwidth (\%) }\end{array}$ & $\begin{array}{l}\text { Gain } \\
(\mathrm{dB})\end{array}$ & $\begin{array}{c}\text { Radiation } \\
\text { efficiency } \\
(\%)\end{array}$ & $\begin{array}{l}\text { Number of } \\
\text { radiation } \\
\text { elements }\end{array}$ & $\begin{array}{c}\text { Resource } \\
\text { consumption }\end{array}$ & Antenna size $\left(\mathrm{mm}^{2}\right)$ & $\begin{array}{c}\text { Beamwidth } \\
(z x \text {-plane and } \\
z y \text {-plane })\end{array}$ \\
\hline [7] & 2.45 & 4.5 & 18.3 & - & 13 & 200 iterations & $387 \times 328 \times 6.9$ & $28^{\circ}$ and $26^{\circ}$ \\
\hline [8] & 2.4 & 25 & 13.7 & - & 7 & $\begin{array}{l}\text { The cluster of } 32 \\
\text { processors } 100 \mathrm{~h}\end{array}$ & $247 \times 250 \times 6.4$ & $46^{\circ}$ and $40^{\circ}$ \\
\hline [9] & 5.8 & 25.6 & 15.1 & - & 7 & $\begin{array}{l}\text { The cluster of } 32 \\
\text { processors } 110 \mathrm{~h}\end{array}$ & $126 \times 100 \times 25$ & $30^{\circ}$ and $28^{\circ}$ \\
\hline [15] & 6.9 & 13 & 18 & - & 13 & - & $142 \times 132 \times 3.3$ & $24^{\circ}$ and $22^{\circ}$ \\
\hline [16] & 7 & 2.3 & 15 & - & 9 & - & $109 \times 109 \times 3.5$ & $40^{\circ}$ and $40^{\circ}$ \\
\hline [18] & 5.4 & 23 & 20 & 51 & 27 & - & $300 \times 125 \times 2.5$ & $20^{\circ}$ and $30^{\circ}$ \\
\hline This work & 2.45 & 7.68 & 16.72 & 98.54 & 8 & $\begin{array}{c}3 \text { hours on } 8 \\
\text { cores with } 32 \mathrm{~GB} \\
\text { of RAM }\end{array}$ & $\begin{array}{c}300 \mathrm{~mm} \times 210 \mathrm{~mm} \times \\
9.9 \mathrm{~mm}\end{array}$ & $\begin{array}{l}18.52^{\circ} \text { and } \\
31.25^{\circ}\end{array}$ \\
\hline
\end{tabular}

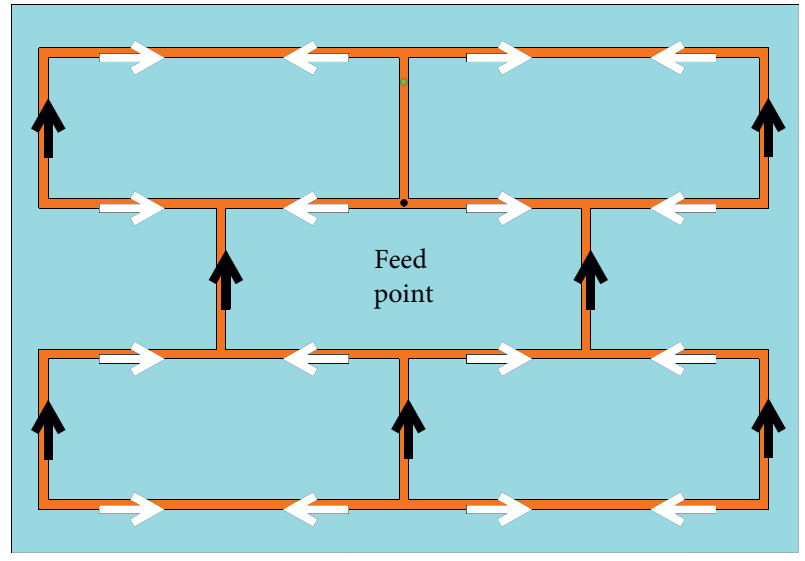

Figure 13: Current distribution.

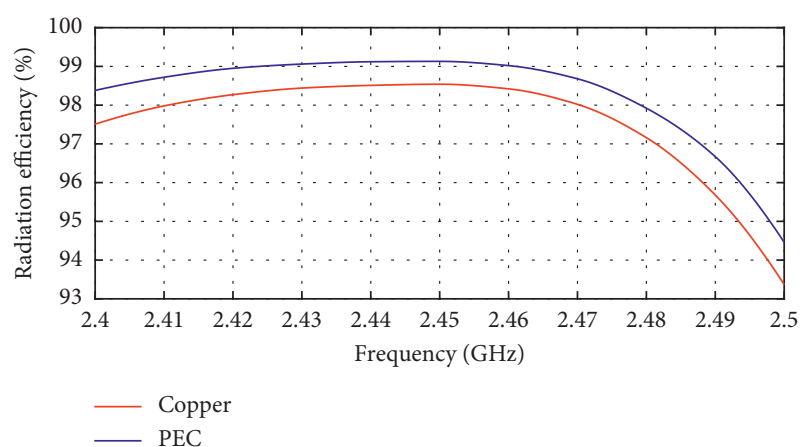

Figure 14: Radiation efficiency.

an impedance of $50 \Omega$ into consideration, which has $0.14 \mathrm{~dB}$ loss per meter. $L_{\text {cable }}$ is multiplied by a factor of 2 because on both transmitter and receiver sides approximately the same length of cables is being used due to antenna height with respect to ground. The height of the antenna is the sum of Fresnel zone around a point-to-point link and curvature of Earth between transmitter and receiver. Both these two heights are measured in meter. So, $L_{\text {cable }}$ can be defined as

$$
L_{\text {cable }}=H_{\text {Fresnel }}+H_{\text {curvatur }} \text {, }
$$

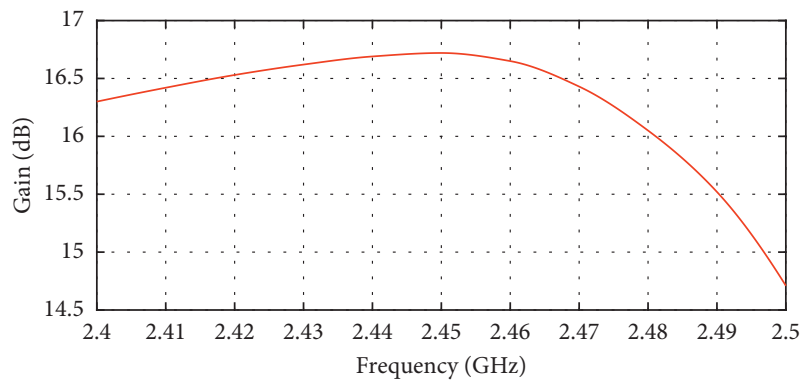

FIGURE 15: Gain.

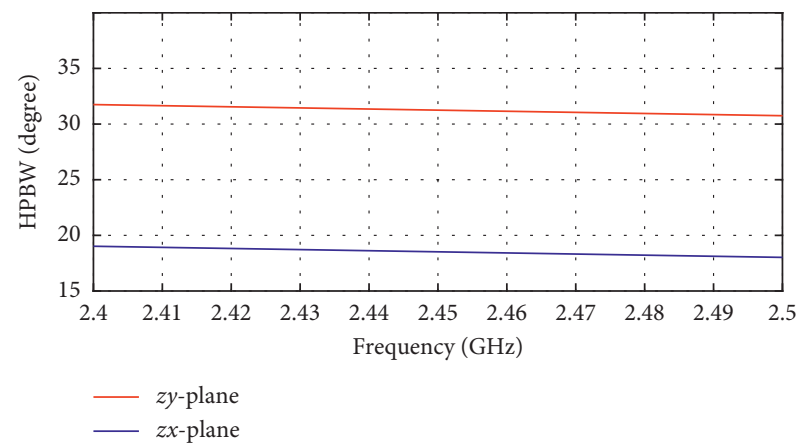

Figure 16: HPBW in $z x$-plane and $z y$-plane.

where $H_{\text {Fresnel }}$ is the antenna height due to Fresnel zone and $H_{\text {curvature }}$ is the antenna height due to curvature of the Earth, which is also measured in meters. For the safe side instead of taking $60 \%$ of the first Fresnel zone, all first Fresnel zones are considered here for link calculation. $\mathrm{H}_{\text {Fresnel }}$ can be defined as

$$
H_{\text {Fresnel }}=17.32 \sqrt{\frac{D}{4 F}} .
$$

Similarly, the curvature of Earth between two points can be defined as

$$
H_{\text {curvature }}=\left(6371-6371 \sin \left(\frac{\pi}{2}-\frac{D}{6371}\right)\right) \times 1000 .
$$




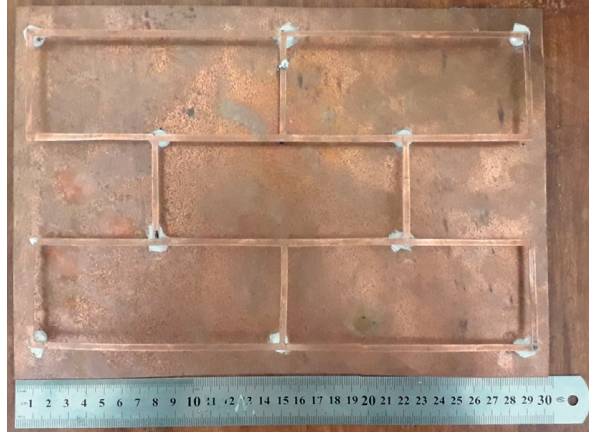

(a)

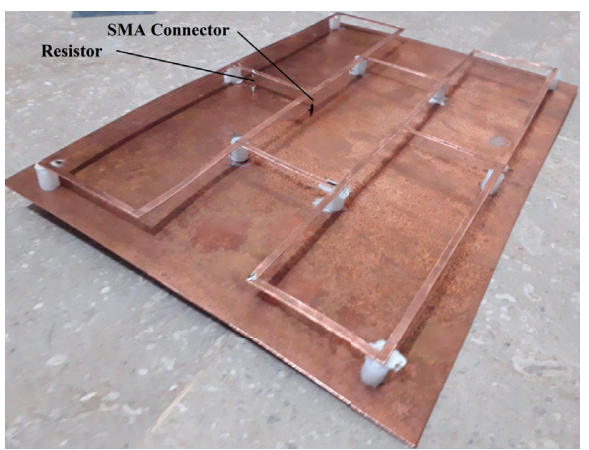

(b)

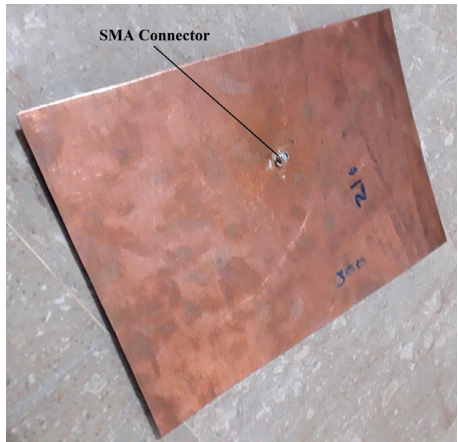

(c)

FIgURE 17: Fabricated antenna: (a) front view; (b) side view; (c) back view.

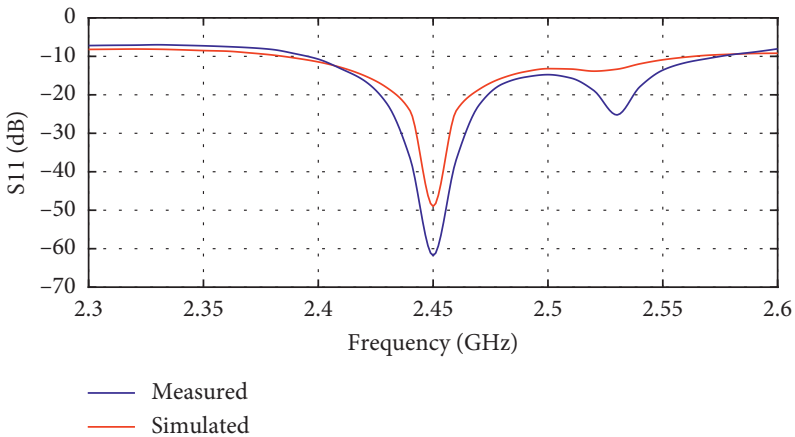

FIGURE 18: Measured versus simulated $S_{11}$ a.

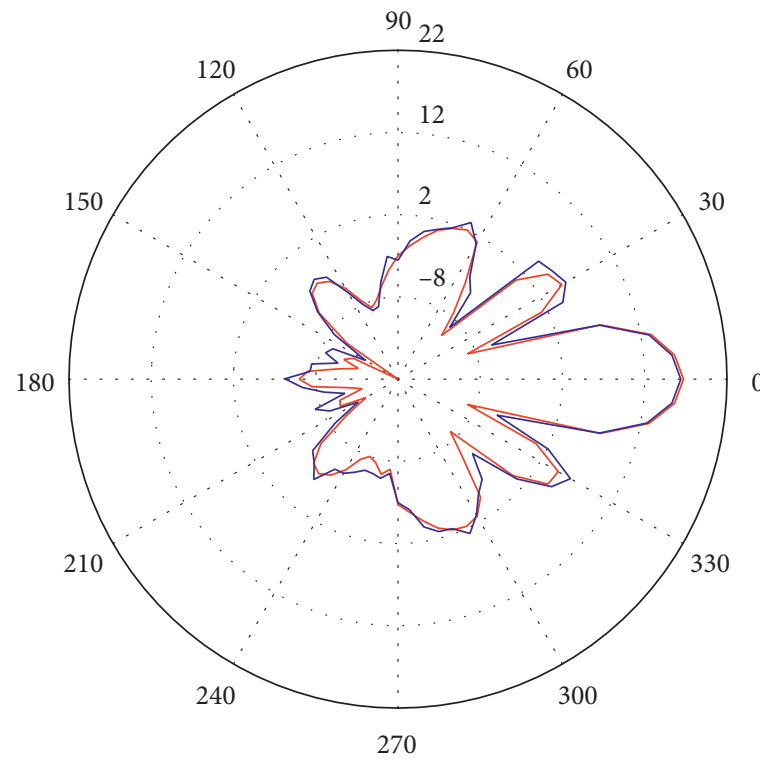

- Simulated — Measured

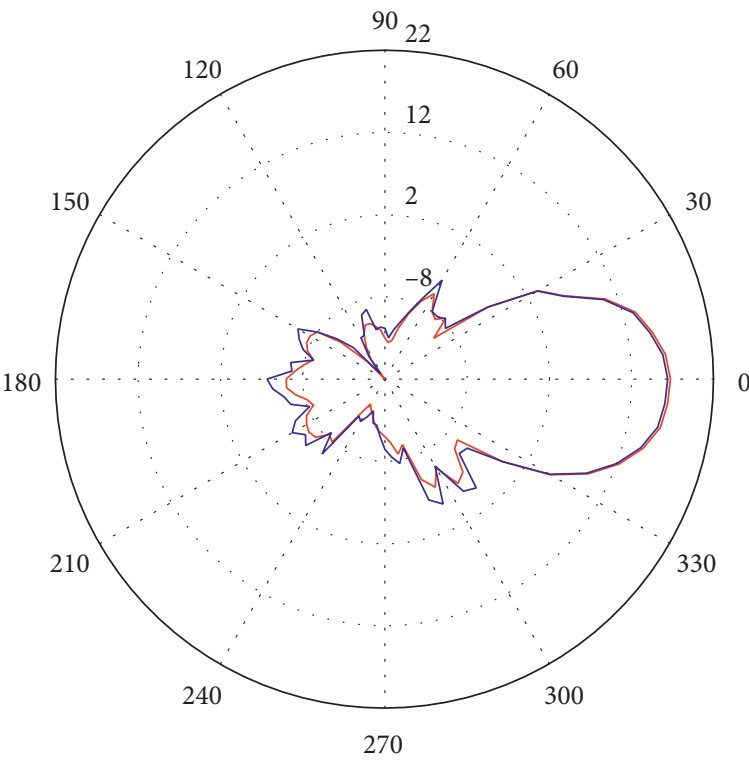

- Simulated

— Measured

(b)

Figure 19: Measured and simulated gains in (a) $z x$-plane and (b) $z y$-plane. 


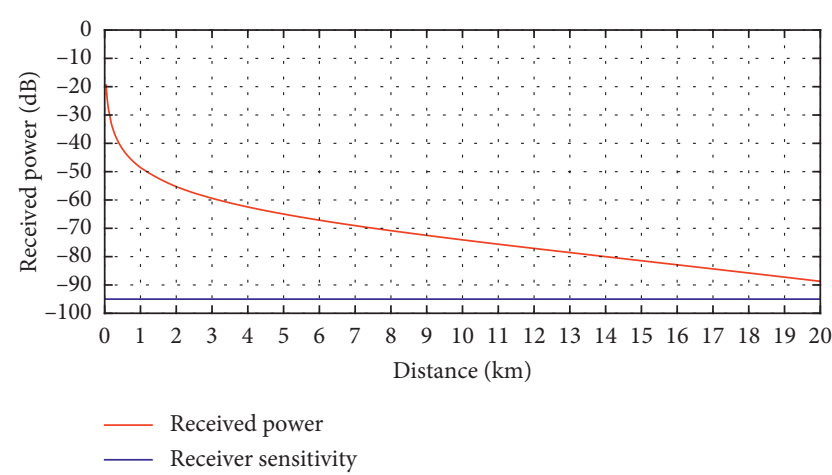

FIgURE 20: Received power versus distance. became

Putting equations (6) and (7) in equation (5), $L_{\text {cable }}$

$$
\begin{aligned}
L_{\text {cable }}= & 0.14 \times\left(17.32 \sqrt{\frac{D}{4 F}}+\left(6371-6371 \sin \left(\frac{\pi}{2}\right.\right.\right. \\
& \left.\left.\left.-\frac{D}{6371}\right)\right) \times 1000\right) .
\end{aligned}
$$

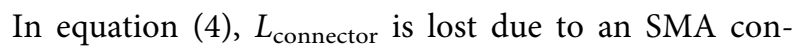
nector, which is multiplied by a factor of 4 assuming a total of four SMA connectors used on both the transmitter and receiver sides. Two connectors are used to connect the transmitter and transmitting antenna, while the other two are used to connect the receiver and receiving antenna. The insertion loss of the SMA connector depends on the frequency, which can be defined as

$$
L_{\text {connector }}=0.03 \sqrt{F} \text {. }
$$

Putting equations (8) and (9) in equation (4), loss due to cables and connectors became

$$
\begin{aligned}
L= & 2 \times 0.14 \times\left(17.32 \sqrt{\frac{D}{4 F}}+\left(6371-6371 \sin \left(\frac{\pi}{2}\right.\right.\right. \\
& \left.\left.\left.-\frac{D}{6371}\right)\right) \times 1000\right)+4 \times(0.03 \sqrt{F}) .
\end{aligned}
$$

If transmitter antenna transmits $20 \mathrm{dBm}$ power and both transmitting and receiving antennas are the same, which have been fabricated in this research to have a gain of $16.72 \mathrm{~dB}$, then, putting values of $P_{\mathrm{t}}, G_{\mathrm{t}}, G_{\mathrm{r}}, \mathrm{L}_{\mathrm{fs}}$, and $L$ in equation (2),

$$
\begin{aligned}
P_{r}= & 20 \mathrm{~dB} \mathrm{~m}+2 \times 16.72 \mathrm{~dB}-\left(20 \log _{10} D\right. \\
& \left.+20 \log _{10} F+92.45\right) \mathrm{dB}-\left(2 \times 0.14 \times\left(17.32 \sqrt{\frac{D}{4 F}}\right.\right. \\
& \left.+\left(6371-6371 \sin \left(\frac{\pi}{2}-\frac{D}{6371}\right)\right) \times 1000\right) \\
& +4 \times(0.03 \sqrt{F})) \mathrm{dB} .
\end{aligned}
$$

Assuming -95 dBm sensitivity of receiver, a graph between distance " $D$ " and received power $P_{\mathrm{r}}$ at frequency $F=2.45 \mathrm{GHz}$ is shown in Figure 19 .

From Figure 20, it can be seen that even at a distance of $20 \mathrm{Km}$ fade margin is still approximately $6 \mathrm{dBm}$ and the signal has considerable strength with respect to the sensitivity of the receiver. So, the antenna can be a suitable candidate for long-range communication in ISM $2.4 \mathrm{GHz}$ band due to its high gain characteristic.

\section{Conclusion}

In this research work, a metallic grid array antenna was designed, which operates in ISM $2.4 \mathrm{GHz}$ band and provides long-range connectivity. The antenna performance in terms of frequency impedance bandwidth and gain was studied. To improve performance, modifications in antenna designs were made. Later, a light optimization was carried out to tune up its performance further. The antenna has high gain, high radiation efficiency, low complexity, and narrow beamwidth. These characteristics make it an ideal candidate for long-range communication in ISM $2.4 \mathrm{GHz}$ band.

\section{Data Availability}

The data used to support the findings of this study are included within the article.

\section{Disclosure}

Syed Mushhad Mustuzhar Gilani and Muhammad Tamur Sultan are co-first authors.

\section{Conflicts of Interest}

The authors declare that there are no conflicts of interest regarding the publication of this paper.

\section{Authors' Contributions}

Syed Mushhad Mustuzhar Gilani and Muhammad Tamur Sultan contributed equally to this work. Syed Mushhad Mustuzhar Gilani supervised and provided intellectual support at each step of this research work. He suggested improvements in the main idea of the research, antenna optimization, and writing of the manuscript. He analyzed the proposed approach and evaluated the obtained results. Mr. Muhammad Tamur Sultan presented the main idea for antenna design, designed it, simulated it, acquired data, and then interpreted it in the form of results. He also performed parametric analysis. Mr. Zeng Shuai contributed with the expert's advice for manuscript drafting, helped in taking practical measurements of antenna fabrication for its performance parameters, and also arranged funding for this research study. Mr. Asif Kabir contributed in revising this research work critically for its important intellectual content so that it can be presented suitably for the publication. All authors read and approved the final manuscript. 


\section{Acknowledgments}

This work was supported by the Prospective Research Project of Natural Science Foundation of Chongqing (no. cstc2018jcyjA0743) and Science and Technology Research Program of Chongqing Municipal Education Committee (no. KJQN201800640).

\section{References}

[1] H. Luo, Z. Huang, and T. Zhu, "A survey on spectrum utilization in wireless sensor networks," Journal of Sensors, vol. 2015, 2015.

[2] A. S. Raval, "Cluster head selection for in wireless sensor networks," International Journal on Computer Science and Engineering, vol. 1, no. 3, p. 6, 2015.

[3] H. Nakano, I. Oshima, H. Mimaki, J. Yamauchi, and K. Hirose, "Numerical analysis of a grid array antenna," in Proceedings of the IEEE, pp. 700-704, Singapore, Singapore, August 2002.

[4] H. Nakano, T. Kawano, and J. Yamauchi, "Meander-line grid-array antenna," IEE Proceedings-Microwaves, Antennas and Propagation, vol. 145, no. 4, pp. 309-312, 2002.

[5] T. Kawano and H. Nakano, "A grid array antenna with C-figured elements," Electronics and Communications in Japan (Part I: Communications), vol. 85, no. 1, pp. 58-68, 2002.

[6] H. Nakano, T. Kawano, Y. Kozono, and J. Yamauchi, “A fast MoM calculation technique using sinusoidal basis and testing functions for a wire on a dielectric substrate and its application to meander loop and grid array antennas," IEEE Transactions on Antennas and Propagation, vol. 53, no. 10, pp. 3300-3307, 2005.

[7] C. Xing, C. Kain, and H. Kama, "A microstrip grid array antenna optimized by a parallel genetic algorithm," Microwave and Optical Technology Letters, vol. 50, no. 1, pp. 2976-2978, 2008.

[8] X. Chen, G. Wang, and K. Huang, "“A novel wideband and compact microstrip grid array antenna," in Proceedings of the International Conference on Microwave and Millimeter Wave Technology, vol. 58, no. 2, pp. 333-336, Chengdu, China, May 2010.

[9] P. Feng, X. Chen, X.-Y. Ren, C.-J. Liu, and K.-M. Huang, "A novel microstrip grid array antenna with both high-gain and wideband properties," Progress in Electromagnetics Research, vol. 34, p. 215, 2012.

[10] J. D. Kraus, "A backward angle-fire array antenna," IEEE Transactions on Antennas and Propagation, vol. 12, no. 1, pp. 48-50, 1964.

[11] R. Conti, T. Dowling, J. Toth, and J. Weiss, "The wire grid microstrip antenna," IEEE Transactions on Antennas and Propagation, vol. 29, no. 1, pp. 157-166, 1981.

[12] T. Kawano and H. Nakano, "Cross-mesh array antennas for dual LP and CP waves," in Proceedings of the IEEE Antennas and Propagation Society International Symposium. 1999 Digest. Held in conjunction with: USNC/URSI National Radio Science Meeting (Cat. No.99CH37010), vol. 4, pp. 2748-2751, Orlando, FL, USA, July 1999.

[13] H. Nakano, T. Kawano, and J. Yamauchi, “A cross-mesh array antenna," in Proceedings of the 11th International Conference on Antennas and Propagation (ICAP 2001), pp. 327-330, Manchester, UK, April 2001.

[14] H. Nakano, T. Kawano, H. Mimaki, and J. Yamauchi, "Analysis of a printed grid array antenna by a fast mom calculation technique," in Proceedings of the 11th International Conference on Antennas and Propagation (ICAP 2001), pp. 302-305, Manchester, UK, April 2001.

[15] H. Nakano, H. Osada, and J. Yamauchi, "Strip-type grid array antenna with a two-layer rear-space structure," in Proceedings of the 7th International Symposium on Antennas, Propagation \& EM Theory, pp. 58-61, Guilin, China, October 2006.

[16] H. Nakano, H. Osada, H. Mimaki, Y. Iitsuka, and J. Yamauchi, "A modified grid array antenna radiating a circularly polarized wave," in Proceedings of the International Symposium on Microwave, Antenna, Propagation and EMC Technologies for Wireless Communications, pp. 527-530, Hangzhou, China, August 2007.

[17] K.-L. Wong and Y.-F. Lin, Microstrip-Line-Fed Compact Broadband Circular Microstrip Antenna With Chip-Resistor Loading, John Wiley \& Sons, Hoboken, NJ, USA, 1998.

[18] H. Nakano, Y. Iitsuka, and J. Yamauchi, "Loop-based circularly polarized grid array antenna with edge excitation," IEEE Transactions on Antennas and Propagation, vol. 61, no. 8, pp. 4045-4053, 2013.

[19] H. Nakano, I. Oshima, H. Mimaki, K. Hirose, and J. Yamauchi, "Center-fed grid array antennas," in Proceedings of the IEEE Antennas and Propagation Society International Symposium. 1995 Digest, vol. 4, pp. 2010-2013, Newport Beach, CA, USA, June 1995.

[20] D. Nalineswari and N. Rakesh, "Link budget analysis on various terrains using IEEE 802.16 WIMAX standard for 3.5 $\mathrm{GHz}$ frequency," in Proceedings of the IEEE International Conference on Electrical, Computer and Communication Technologies (ICECCT), Coimbatore, India, March 2015. 